\title{
A survey of the knowledge, attitude and awareness of principles and practices in Orthodontics among general dentists and non- orthodontic specialists
}

\author{
S. Niveda, Dr.Saravana Dinesh
}

\begin{abstract}
A questionnaire survey was conducted to evaluate the knowledge, attitude and awareness in the field of Orthodontics amongst general dentists and non orthodontic specialists. The questionnaire consisted of fifteen (15) questions related to diagnosis and treatment planning in Orthodontics. It was distributed to one hundred $(n=100)$ general dentists and non-orthodontic specialists. After computing the data, we observed that the knowledge level among the study participants was moderately satisfying. Yet the need for more education of the dentists in certain areas of Orthodontics was perceived. It would help them to identify malocclusions in their patients and increase the awareness regarding dental disease and management among their patients. Knowledge regarding the duration of the retainers was observed to be inadequate. Improving the awareness amongst the practitioners in this area can help the patients with malocclusion to opt for orthodontic treatment at earlier stages and avoid complications later in the future. The study highlights on the need for more CDE (Continuing Dental Education) programs with active participation of general dentists and non-orthodontic specialists to update them. Further, modifications in the education system at the under graduate level in dental colleges to impart more diagnostic concepts can benefit the students.
\end{abstract}

\section{Objectives}

- To evaluate the knowledge, attitude and awareness in the field of Orthodontics among dentists and specialists from other disciplines of Dentistry.

- To evaluate the knowledge and ability to correlate concepts in Orthodontics and other disciplines of Dentistry.

- To assess the importance given to Orthodontics by general dental practitioners and non-orthodontic specialists.

- To suggest and incorporate change in the dental syllabus in colleges to help the students to be more aware of the recent advances in Orthodontics.

\section{Materials and Method}

A structured questionnaire was framed containing 15 questions. The questions addressed various aspects like the understanding of general dentists and non-orthodontic specialists about Orthodontics, their opinion regarding orthodontic treatment planning for patients and knowledge regarding functional appliances and similar concepts pertaining to orthodontic treatment of patients. The questionnaire was distributed to general dentists and specialists other than orthodontists practicing in Chennai city. It was also distributed to post graduate students of all specialties of Saveetha Dental College (other than orthodontists). Total number of dentists who answered the questionnaire was one hundred $(n=100)$. The participants ranged from freshly passed out general practitioners who were abreast of the latest technologies to the elderly practitioners who based their practice on not so up to date treatment strategies. Data was analyzed and descriptive statistics were computed using SPSS Version 17 (Table 1).

\section{Results:}

The participants of the study $(\mathrm{n}=100)$ ranged from young and recently passed out general practitioners / specialists who were abreast of the latest treatment options to the elderly practitioners who based their practice on not so up to date treatment strategies. According to the study participants, the maximum age up to which orthodontic treatment can be carried out was 40.32 \pm 9.24 years and the right age to start orthodontic treatment was $22 \pm 12.75$ years.

When the dentists were questioned if malocclusions can be treated during mixed dentition stage, $96 \%$ of them answered affirmatively. (Yes $=96 \%$; No $=4 \%$ ). About $97 \%$ of them were aware of the availability of functional appliance therapy as a treatment option. The fact that functional appliance can produce the best results when given during pre-pubertal growth spurt was approved positively by $87 \%$ and denied by $13 \%$. When 
the practitioners were questioned if they always asked their patients to report for orthodontic treatment only after all the permanent teeth had erupted, $65 \%$ of the dentists answered "No", while $35 \%$ answered "Yes". Awareness regarding the existence of skeletal malocclusions when patients met their dentists with complaints of proclined teeth and incompetent lips was evaluated. It was observed that $89 \%$ of the dentists were aware of the skeletal malocclusions, while $11 \%$ were not.

The general dentists and other specialists were questioned to find out if they thought that orthodontic treatment always required extraction to which a very small percentage of dentists answered affirmatively (Yes = $7 \%)$. Majority of them (93\%) were aware that it was not an absolute necessity. The influence of orthodontic therapy on the cure of temporo mandibular joint (TMJ) disorders when tested showed that $73 \%$ believed that it can cure TMJ disorders while $27 \%$ did not believe so.

It was encouraging to notice that all the study participants resorted to the assistance of Orthodontists for the management of patients with orthodontic issues. When patients reported with complaints other than orthodontic issues, $85 \%$ of the dentists looked for malocclusions on clinical examination as a routine, while 15 $\%$ failed to look for them. Around 31\% recommended orthodontic treatment for patients with periodontal problems while $69 \%$ did not. Orthodontic treatment was denied for patients with missing molars by only a small proportion of dentists $(8 \%)$. Among all the study participants, $79 \%$ were aware that mini screws can replace molars for anchorage while $21 \%$ were ignorant of this concept. Finally, their opinion as to how long the retainers should be worn after fixed appliance therapy was taken. The results were widely variable with durations ranging from six months to life long.

\section{Discussion}

The questionnaire survey was conducted to evaluate the knowledge, attitude and awareness in the branch of Orthodontics amongst general dental practitioners and dentists from all specialties except Orthodontics. The survey revealed some interesting findings that reflected the existing scenario of orthodontic practice as perceived by dentists from other specialties. The knowledge and awareness prevalent among the study participants was moderately satisfactory. But the study results definitely highlight the need for more education of practice and treatment concepts in Orthodontics to the dentists who did not belong to this field. There is evidence that features like traumatic deep overbite, unprotected incisors and impacted teeth may adversely affect the longevity of the dentition ${ }^{[4]}$. Various habits such as finger and thumb sucking, etc., may lead to serious malocclusions that may require even more complicated surgical and orthodontic measures ${ }^{[5,6]}$. The awareness regarding such basic facts and recent treatment options is mandatory. Therefore, continuing dental education programs are the need of the hour to constantly update the recent advances among the general dentists. It would be also definitely beneficial if the curriculum in the dental colleges and universities can be modified and upgraded to include the modern concepts and therapeutic options.The under and post graduate students can be trained right from the student days and can be exposed to multi disciplinary recent updates. We plan to conduct the study on a larger population in the forth coming days to have a more precise evaluation of the existing scenario.

\section{Conclusion}

From the above study conducted, it was observed that most of the general dentists and non-orthodontic specialists were aware of the basic concepts of Orthodontics like age criteria for orthodontic treatment, diagnosis of malocclusion, and the need for orthodontic treatment. Conduct of Continuing Education programs to update them regularly in diagnosis of orthodontic problems, functional appliance therapy, management of periodontally compromised cases, use of orthodontic mini screws and retention protocol after orthodontic treatment might be of great help to the practitioners in providing meticulous care to their patients.

Table 1: Descriptive statistics of the questionnaire survey - Perception of orthodontics by non orthodontic specialists and general dentists

\begin{tabular}{|l|l|l|}
\hline Q. No. & Survey Question & $\begin{array}{l}\text { Reply with Descriptive } \\
\text { statistics }\end{array}$ \\
\hline 1 & Maximum age upto which orthodontic treatment can be carried out & $40.32 \pm 9.24$ years \\
\hline 2 & Right age to start orthodontic treatment & $12.75 \pm 3.91$ years \\
\hline 3 & Can malocclusions can be treated during mixed dentition stage & Yes $=96 \%, \mathrm{No}=4 \%$ \\
\hline 4 & Aware of functional therapy & Yes $=97 \%, \mathrm{No}=3 \%$ \\
\hline 5 & $\begin{array}{l}\text { Functional appliance gives best result when given during pre-pubertal growth } \\
\text { spurt }\end{array}$ & Yes $=87 \%, \mathrm{No}=13 \%$ \\
\hline 6 & $\begin{array}{l}\text { Do you ask your patients to report for orthodontic treatment only after all } \\
\text { permanent teeth have erupted }\end{array}$ & Yes $=35 \%, \mathrm{No}=65 \%$ \\
\hline 7 & $\begin{array}{l}\text { Aware of skeletal malocclusions when patients come to you with complaint of } \\
\text { proclined teeth and incompetent lips }\end{array}$ & $\mathrm{Yes}=89 \%, \mathrm{No}=11 \%$ \\
\hline 8 & Orthodontic treatment always requires extraction & Yes $=7 \%, \mathrm{No}=93 \%$ \\
\hline
\end{tabular}




\begin{tabular}{|l|l|l|}
\hline 9 & Orthodontic therapy can cure temporo mandibular joint disorders & Yes $=73 \%, \mathrm{No}=27 \%$ \\
\hline 10 & Specialist (orthodontist) is called for opinion & Yes $=100 \%$ \\
\hline 11 & $\begin{array}{l}\text { Looks for malocclusions on clinical examination when patients report with } \\
\text { any other complaint }\end{array}$ & Yes $=85 \%, \mathrm{No}=15 \%$ \\
\hline 12 & Recommends orthodontic treatment for patients with periodontal problems & $\mathrm{Yes}=31 \%, \mathrm{No}=69 \%$ \\
\hline 13 & Denies orthodontic treatment for patients with missing molars & $\mathrm{Yes}=8 \%, \mathrm{No}=92 \%$ \\
\hline 14 & Aware that mini screws can replace molars for anchorage & Yes $=79 \%, \mathrm{No}=21 \%$ \\
\hline 15 & How long should the retainers be worn after fixed appliance therapy & $\begin{array}{l}\text { Widely variable range extending } \\
\text { from } 6 \text { months to life long }\end{array}$ \\
\hline
\end{tabular}

\section{References:}

[1] N.W.Berk, H.Dukich Bush, J.Cavalier, R.Kapur, D.Studen-Pavlovich,J. Sciote and R. J. Weyant. Perception of Orthodontic Treatment Need: Opinion Comparisons of Orthodontists, Paediatric Dentists and General Practitioners. J. Orthod. December 2002 29:287-291.

[2] O’brien Kd, Mccomb J1, Wright.J. Do Dentists Refer Orthodontic Patients Inappropriately? Br. Dent J 2001; 181; 132-136

[3] Beglin Fm, Firestone Ar Vig Kwl, Beck Fm, Kuthy Ra, Wade D.A. A Comparison Of The Reliability And Validity Of 3 Occlusal Indexes Of Orthodontic Treatment Need. American Journal Of Orthodontics And Dentofacial Orthopaedics 2001; 120;240-246.

[4] W.C.Shaw, M.Addy, C.Ray. Dental And Social Effects Of Malocclusion And Effectiveness Of Orthodontic Treatment ;A Review. Journal Of Community Dentistry And Oral Epidemiology. Vol 8, Issue No 1, Pg 36-45, Feb 1980.

[5] D.A.Campell Reid, FRCS (Eng) (Honorary Consultant Plastic Surgeon), A.H.K.Price, FDS, DOrth, RCS(Eng) ( Consultant Orthodontist). Digital Deformities And Dental Malocclusion Due To Finger Sucking. Br. Journal Of Plastic Surgery Volume 37, Issue 4, October 1984, Pages 445-452.

[6] Valeria Luzzi, Marinella Guaragna, Gaetano Lerardo, Matteo Saccucci, Giuliana Consoli, Anna Rita Vestry, Antonella Polimeni. Malocclusions And Non-Nutritive Sucking Habits: A Preliminary Study. Progress In Orthodontics. Volume 12, Issue 2, November 2011, Pages 114-118. 